\title{
Novel Causality in Consumer's Online Behavior: Ecommerce Success Model
}

\author{
Amna Khatoon \\ Department of Software Engineering \\ Bahria University Islamabad, Pakistan \\ Shahid Nazir Bhatti \\ Senior Assistant Professor \\ Department of Software Engineering \\ Bahria University Islamabad, Pakistan
}

\author{
Atika Tabassum, Aneesa Rida \\ Dept. of Software Engineering \\ Bahria University Islamabad, Pakistan \\ Sehrish Alam \\ Dept. of Software Engineering \\ Bahria University Islamabad, Pakistan
}

\begin{abstract}
Online shopping (e-Shopping) has grown at a rapid pace with the advancement in modern web technologies, there are then socio and technical aspects (factors) in the mentioned eshopping. The following research paper highlights some mandatory socio-technical factors affecting consumer's behavior in online shopping environment. In this work a comprehensive conceptual model is put forward based on proposed reform DeLone and McLean Success Model for Information Systems. This model is used for the assessment of the success of eCommerce web portals. Approximately thirteen different hypotheses are proposed on the bases of this methodology which represent the cause and effect relationship among the various variables affecting consumer's online buying behavior. Further this work is simulated in iThink technology to show prominently that consumer's satisfaction and trust directly affects productivity of the organization. For development organizations the proposed methodology is valuable because it will facilitate in building the eCommerce websites, web portals whereas retailers can improve the productivity of their organization by accomplishing this.
\end{abstract}

Keywords-Online shopping; Consumer behavior; E-marketer; Usability; DeLone \& McLean; eCcommerce success model; Causal loop diagram; iThink; Simulation; Evaluation; Retailer

\section{INTRODUCTION}

In recent times eCommerce has gained recognition with the advent of internet. Retailers can sell their products online and customers can search products suitable for them. Online shopping differs from brick-and-mortar shopping businesses in many ways; be it the physical presence needed for traditional shopping, convenience, reasonable price, product variety, and promotions in online shopping, it has taken incredible acclaim amongst everyone. Retailers, suppliers, marketers can expand their business because of low distribution cost and consumers can find and get the best product available on the internet. Retailers should be aware how to gain consumer's trust and satisfy them.

Consumers can buy products and services faster, anywhere and anytime at reasonable price from an online shopping website [1]. Retailers have to understand consumer's needs and wants beforehand to give them the best online experience possible. In order to do that they have to understand the psychological state of the consumer who shop online [2] and their behavior and what can affect it.

The online shopping behavior process consists of five steps [3]. First, the customer identifies the need or wants for a purchase and defines requirements for it. Secondly, they search for the product from the options available to them. Once they find the right product for them, they'll buy it after the process of elimination and comparison of prices. Lastly, consumers will have to decide the shipping costs, and delivery mechanism.

Several factors can affect the end user's online purchase behavior such as subjective norms (culture, trust), system quality (website quality, interactivity, ease of use, promotions) and service quality (responsiveness, security, price, reliability, alternatives).

There are eight sections in this research paper. Section I is Introduction, Section II is for Materials and methods, Related work is in Section III, Conceptual model is in Section IV, Hypotheses regarding factors affecting consumer online shopping behavior are in Section V, Causal loop diagram is in Section VI, Simulation and results are in Section VII, and finally Section VII is the conclusion.

\section{MATERIALS AND METHODS}

\section{A. eCcommerce}

eCommerce is a business platform, where anyone can buy, sell and transfer goods, information and services through electronic means usually over the internet. Anything can be offered to the end users via ecommerce, from concert tickets to books to commercial services. eCommerce includes Business-to-Consumer model(B2C), where consumers can buy goods or services directly from the source (business). Online shopping or e-tailing is an example of B2C.

\section{B. Online Shopping}

In 1979, Michael Aldrich invented online shopping. It can also be called e-tail from 'electronic retail' or e-shopping. Online shopping is where users can use web browser to buy goods or services over internet. 
Consumers can enjoy the convenience of online shopping from anywhere and businesses can thrive on low overhead. Online shopping is ideal for small business as they don't need huge amount of merchandise stocked or a retail store.

Internet has created an exceedingly cutthroat market where retailers are vying for customer's attention. Since there are so many potential consumers, it is paramount that retailer are able to understand what the consumer wants and needs and identify the influencing factors affecting consumer behavior.

\section{Consumer Behavior}

Sabine Kuester, [4] defines consumer behavior as the processes and ideas, the individuals and groups exercise to satisfy their needs. Every human being has a different personality so their buying behavior is also different from one another. Consumer behavior is influenced by cultural trends, social drivers (family, social status), personal factors (age, lifestyle, and revenue), psychological factors (motivation, perception and attitude) and risks perceived by the user.

\section{RELATED WORK}

There are multiple studies available regarding what factors influence consumer's online shopping behavior. The most important and common factors were found to be consumer's trust, e-loyalty and consumer's satisfaction.

Shankar et al. [23] discussed online trust in relation to different types of stakeholders: customers, dealers, stockholders, distributors and partners. They presented a conceptual framework for factors which are relevant to online trust including website and user attributes (such as security, brand, etc.). Trust then influences customer satisfaction, customer loyalty and performance of the ecommerce website.

Aghdaie et al. [9] suggested that consumer's trust is the main influence in eCommerce transactions. The authors made hypotheses from a survey study, discussing the factors in terms of trustee, trustor and environment to build trust, purchase and recurring purchase. Some of the factors affecting consumer's attitude of trust are promotions, government policies, payment methods and delivery mechanism, information quality and design, and usability of the website.

Uzun and Porturak [27] examined Bosnian online ecommerce customers and discussed the relationship between e-satisfaction and e-loyalty. E-loyalty was referred in terms of repurchases, demographics, age, gender, education and revenues. They proposed seven hypotheses concerning trust, satisfaction and online shopping behavior. Consumer's trust, price, convenience, web design, quality of product, delivery time, and previous experience positively affects consumer behavior and their satisfaction. Zhu et al. [22] also support that trust and customer satisfaction are the primary factors that have an impact on customer's loyalty to the eCommerce website.

Chandra and Sinha, [24] studied the factors affecting the consumers of online shopping in an Indian city, Bhilai-Durg. They presented several hypotheses that the consumer intention to buy thing online depends upon demographics, attitude of the consumer, convenience, price and trust. These hypotheses were tested through the result from 100 questionnaires.

Park and Kim, [6] conducted a survey of 602 Koreans who bought books online. They found that UI quality, content quality, and secure payments were some of the factors influencing consumer's purchase behavior and their commitment to the website.

Akbar and James, [7] identified the nine variables (Price, Auction websites, Refund policy, Convenience, Security, Search engines, Product Brand, Promotions and malls) as the independent factors that influence consumer behavior. They gathered data from employees of "crazy domains" from Nonthaburi, Thailand. Using t-test analysis for gender they showed that females tend to shop online more than men.

Javadi et al. [25] presented a conceptual model for online consumers of Iran, which represent social and technical factors that affect consumer online shopping behavior. They surveyed 200 users and found that unsecure transactions and non-delivery of the items purchased by the user have negative impact on consumer behavior.

$\mathrm{Li}$ and Zhang, [8] analyzed 35 empirical articles to investigate online shopping attitudes and behaviors. Ten factors were identified as demographics, environment, user and item's attributes, attitude, buyer's intention to purchase goods and their buying behavior, and consumer satisfaction.

Hung and McQueen, [10] proposed an evaluation mechanism for the evaluation from first-time consumer's perspective of an online shopping website. Three failure points were identified to measure the satisfaction and dissatisfaction of consumer.

Khanh and Gim, [26] performed an empirical study on 238 Vietnam consumers who shop online. They proposed a conceptual model having several factors that affect consumer's online shopping behavior such as: price, ease of use, payment method, security, and content privacy of the website.

DeLone and McLean [11] presented an eCommerce success model which included six dimensions: System quality, Service quality, Information quality, Use, Customer satisfaction and Net benefits. They also reviewed old and new eCommerce success metrics from different authors, which they applied to two case studies to justify their model.

Laurae'us et al. [12] discussed that searching process and searching mechanisms for finding the perfect product, while shopping online are essential to customer's satisfaction.

Sinha and Kim [28] proposed a conceptual model for factors affecting Indian online shopping customers. This model examined there are financial, product and convenience risks associated with consumers attitude to shop online. Delivery concerns and return policies also influence consumer's behavior and attitude towards online shopping.

In Table I. multiple studies are shown in a tabular form, regarding the several factors which influence consumer's online shopping behavior. 
TABLE I. DIFFERENT STUDIES ON FACTORS AFFECTING CONSUMER'S ONLINE SHOPPING BEHAVIOR

\begin{tabular}{|c|c|}
\hline Factors & Authors \\
\hline Trust & $\begin{array}{l}\text { Shanker et al. [23], Chandra and Sinha [24], } \\
\text { Aghdaie et al. [9], Khanh and Gim [26], } \\
\text { DeLone and McLean [11], Zhu et al. [22], } \\
\text { Cheung \& Lee 2006, Crye et al. 2005, } \\
\text { Jarvenpaa \& Tractinsky 1999, Bhatnagar et al. } \\
\text { 2000, Doolin et al., 2005, Gupta et al. 2003, Lee } \\
\text { \& Turban 2001, Gommans et al. 2001, Pavlou } \\
\text { 2003, Uzun and Porturak [27] }\end{array}$ \\
\hline Demographics & $\begin{array}{l}\text { Li \& Zhang [8], Chandra and Sinha [24], Uzun } \\
\text { and Porturak [27], Bellman et al., 1999, } \\
\text { Bhatnagar et al., 2000, Kunz 1997, Sultan \& } \\
\text { Henrichs 2000, Weiss 2001, Swinwyard \& } \\
\text { Smith } 2003\end{array}$ \\
\hline $\begin{array}{l}\text { Availability of } \\
\text { information }\end{array}$ & $\begin{array}{l}\text { Aghdaie et al. [9], DeLone and McLean [11], } \\
\text { Elliot \& Speck 2005, Quinn 1999, Bart et al. } \\
\text { 2005, Brown et al. 2001 }\end{array}$ \\
\hline Price & $\begin{array}{l}\text { Chandra and Sinha [24], Akbar and James, [7], } \\
\text { Khanh and Gim [26], Sinha and Kim [28], } \\
\text { Spann \& Tellis 2006, Chung \& Shun 2008, } \\
\text { Cuneyt \& Gautam 2004, Heim \& Sinha 2001 }\end{array}$ \\
\hline Responsiveness & Cheung \& Lee 2005 \\
\hline Ease of use & $\begin{array}{l}\text { Shanker et al. [23], Aghdaie et al. [9], Khanh } \\
\text { and Gim [26], Dabholkar 1996, Santos 2003, } \\
\text { Pavlou 2003 }\end{array}$ \\
\hline Security & $\begin{array}{l}\text { Shanker et al. [23], Park and Kim [6], Akbar } \\
\text { and James [7], Javadi et al. [25], Aghdaie et al. } \\
\text { [9], Khanh and Gim [26], Kesh et al., 2002, Rao } \\
2000\end{array}$ \\
\hline Decision aids & $\begin{array}{l}\text { Geiss lee \& Zinkhan 1998, Haubl \& Murray } \\
\text { 2003, Xio \& Benbast 2007, Huang \& Sycara } \\
\text { 2002, Huang \& Lin } 2007\end{array}$ \\
\hline UI quality & $\begin{array}{l}\text { Li \& Zhang [8], Shanker et al. [23], Park and } \\
\text { Kim [6], Aghdaie et al. [9], Khanh and Gim } \\
\text { [26], DeLone and McLean [11], Uzun and } \\
\text { Porturak [27] Nali \& Phing Zhang 2002, } \\
\text { Zhang, Von Dran, Small \& Barcellos } \\
\text { (1999,2000), Zhang \& Von Dran 2000 }\end{array}$ \\
\hline Interactivity & $\begin{array}{l}\text { Shanker et al. [23], Aghdaie et al. [9], Haeckel } \\
\text { 1998, Hoffman \& Novak } 1996\end{array}$ \\
\hline Reliability & $\begin{array}{l}\text { Parasuraman et al., 1988, Janda et al., 2002, } \\
\text { Kim \& Lee } 2002\end{array}$ \\
\hline Brand & Shanker et al. [23], Akbar and James [7] \\
\hline Convenience & $\begin{array}{l}\text { Chandra and Sinha [24], Akbar and James, [7], } \\
\text { Javadi et al. [25], Sinha and Kim [28] }\end{array}$ \\
\hline $\begin{array}{l}\text { Customer } \\
\text { satisfaction }\end{array}$ & $\begin{array}{l}\text { Li \& Zhang [8], Shanker et al. [23], Aghdaie et } \\
\text { al. [9], Khanh and Gim [26], DeLone and } \\
\text { McLean [11], Zhu et al. [22], Uzun and } \\
\text { Porturak [27] }\end{array}$ \\
\hline $\begin{array}{l}\text { Customer } \\
\text { loyalty }\end{array}$ & $\begin{array}{l}\text { Li \& Zhang [8], Shanker et al. [23], Aghdaie et } \\
\text { al. [9], DeLone and McLean [11], Zhu et al. } \\
\text { [22], Uzun and Porturak [27] }\end{array}$ \\
\hline
\end{tabular}

\section{CONCEPTUAL MODEL}

The conceptual model proposed here is the modified form of DeLone and McLean model for eCommerce success. Incorporated in this conceptual model, are some social and technical factors which influence customer shopping behavior. This model can be used to assess eCommerce website success and help retailers to keep their customers and increase their organization's productivity. Seven segments of this model are as follows:

\section{A. Information Quality}

The quality of information of an eCommerce website depends upon the completeness, correctness and relevance of the content of the website. Comprehensive information about the product has a huge impact upon buyer's intention to use the website and buyer's satisfaction.

\section{B. System Quality}

The quality of the system can be referred to as ease of use, user interface quality and interactivity, search engine optimization and decision aids. It indirectly impacts the productivity of the organization through usage intentions and consumer's satisfaction.

\section{Service Quality}

The service quality can be defined in terms of responsiveness of the system, secure transactions, Promotions, lower cost and reliability (refund policies, on time product delivery). It impacts consumer's usage and satisfactions which in turn impacts the productivity.

\section{Intention to use}

Consumer's intention to use is influenced by information, system and service quality. Culture and demographics also influence the user's usage of the system. It in turn effects user's satisfaction.

\section{E. User satisfaction}

End user's satisfaction is the extent to which a consumer is contended with the system and is influenced by consumer's usage of the system. If a consumer is pleased with the system there is a chance of repeat purchase.

\section{F. User loyalty}

User satisfaction directly impacts user's loyalty. If a consumer is satisfied with the website's quality and service, it is most likely that the consumer visits the website again to make purchase. Trust is the critical factor in consumer's loyalty which in turn also impacts user satisfaction.

\section{G. Productivity}

Customer's intent to use the system and their loyalty to the system affects the productivity of the system. It refers to how much an organization has profited from consumer's responsiveness. Productivity then impacts user's usage and user loyalty. 


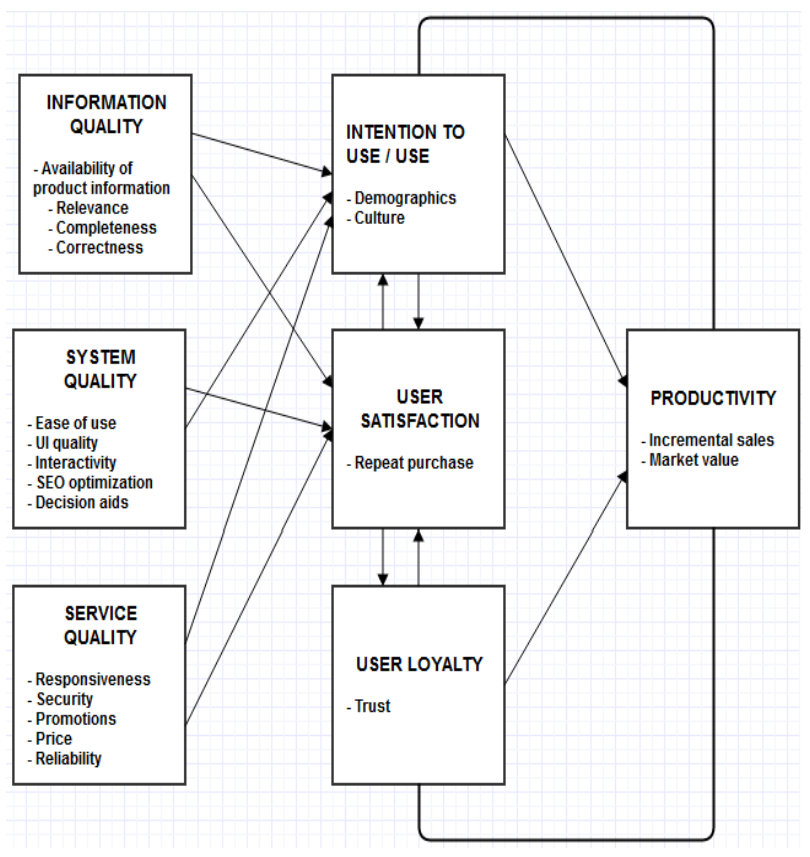

Fig. 1. Conceptual model for eCommerce website success

\section{HYPOTHESIS ON FACTORS AFFECTING CUSTOMER BEHAVIOR IN AN ONLINE SHOPPING ENVIRONMENT}

From the conceptual model discussed in Section IV, thirteen hypotheses can be made regarding the factors influencing customer's online shopping behavior.

\section{A. Social Aspects}

1) Culture: Culture can be defined as the joint characteristics of the minds that differentiate individuals from one another [13]. The values and beliefs that affect how we perform a task and make decisions are ingrained, in us from our childhood [14]. Therefore, these traits are important to emarketers. Marketers have to understand the user's cultural background in order to predict their buying behavior. The consumer's background knowledge, their core value and norms help the marketers to produce potential goods that satisfy consumer's needs.

Internet has the capability to reach people of every culture around the globe. Marketers will have to instigate consumers in accepting the custom of online shopping in the fabric of society. online.

H1: Culture positively affects consumer's intention to shop

2) Cost: Price is a critical factor for consumers who shop online [15]. Several consumers don't bother to explore further if the price is not reasonable. Shopping online allow users to gather and compare product information such as price. Furthermore, extra charges such as shipping cost, customs or extended delivery times can affect consumer's decision to buy a product even if its price is reasonable.

Nevertheless, Li et al. argues that often online shoppers don't care about price as the price difference is very small and comparison of products cost is time consuming.
H2: Price of the product positively affects customer satisfaction.

3) Demographics: Demographics incorporate age, gender, revenue, academic qualification and time spent online of an end user. It essentially, tells whether the end users surf the internet or not, but once the end user is online, demographics doesn't affect their purchasing activities.

Consumer belonging to higher social class and higher education, shop more online, then consumers of lower social class and less education because of the availability of financial resources and awareness [5]. Some studies show that females tend to shop more online then men, while other studies show opposite.

H3: Demographics positively affect the consumer's intention to shop online.

4) Convenience: Something that saves time and effort is convenient. It is undeniable that a person's life has become hectic in this age, so modern technology can be reckoned as the solution to the consumer's worries of in store peak hour crowds. Shopping online is very convenient to consumers as they can access the website from anywhere anytime if they do not mind waiting for extra shipping time and delivery costs.

In the business context, the presence of internet has liberated retailers from traditional marketing practices. Online shopping has provided retailers a platform to grow their profits by developing better marketing communication strategies [16].

H4: Convenience positively affects consumer's satisfaction.

5) Availability of product information: Availability of product information affect consumer's trust [17], as consumer cannot physically examine the product while shopping online. Marketers have difficulty in establishing consumer's trust in online shopping environment [18].

Therefore, it is important to provide detailed information of the product to help build user confidence, that they made the right decision in buying the product. Constant updates in product information helps consumer to keep track of the product [19].

H5: Availability of product information positively affects consumer's trust.

6) Trust: Trust, is essentially the most significant cause that influence consumer's behavior while shopping online. The definition of online trust varies with the stakeholders. From a consumer's point of view, an eCommerce website must be secure and reliable. Whereas, from a seller's viewpoint the website key constituents may be integrity, competence and confidentiality [11].

H6: Trust positively affects consumer's satisfaction.

\section{B. Technical Aspects}

1) User Interface Quality and interactivity: Consumers are attracted to the websites because of their design features, quality and interactive interfaces. The higher the website 
quality, the higher is a chance of consumer shopping there. The quality of the shopping website leads to consumer's satisfaction and dissatisfaction and in consumer's revisiting it. However, bad website features and quality can hinder consumer's online shopping behavior as they directly impact on users [3]. The user interface of the website should be attractive and appealing to grab consumer's attention while showing the essence of website.

Appropriate font and color schemes, clear navigation, responsive website design, cross browser functionality should be present to appeal the customer. Appropriate help and search engine optimization of the website should be provided [22]. Feedbacks from consumers can help in understanding their problems and improving website design quality.

H7: User interface quality and interactivity positively affects consumer's satisfaction.

2) Ease of use: Online shopping website must have ease of use, i.e. every kind of user can easily understand and use the website. The usability factor is critical in maintaining customer trust in online shopping environment.

Clear and visible navigations, consistent styles and color, concise content, appropriate help and searching means easily accessible are various usability factors to affect end user's satisfaction.

H8: Ease of use positively affects consumer's satisfaction.

3) Decision aids: Decision making in an online shopping environment includes searching for product information, comparison of prices, and choosing alternatives.

Typically, consumers will rather view the price of a product first, than any other information about the product. There are same products available of different brands with different prices. The consumers can choose the products through comparing prices using decision aids. Interactive decision aids are used to facilitate consumers to form intelligent decisions [13]. These decisions directly influence consumer's satisfaction and their purchasing behavior.

Recommendation agent and comparison matrix are the two main interactive decision making tools available to help consumers to make the right decision. Alternatives should be available to consumers in term of searching and payment methods. The user may choose from related products and pay through different mechanisms such as PayPal, credit card, Bit coin, cash on delivery etc.

H9: Decision aids positively affect consumer's satisfaction.

4) Responsiveness: In this era online shopping is preferred compared to traditional shopping because of its convenience. This means that online shopping is time effective. The consumers will prefer the system whose order processing and transaction takes less time. If the system is not responsive, the consumer will not buy from that website.

H10: Responsiveness positively affects consumer's satisfaction.
5) Security: There are many benefits of online shopping but there are security risks involved. Security is one of the main attributes which can limit consumer's buying over the internet, as they fear for the security of their sensitive information [21]. The consumers fear disclosure of their personal information (address, contact information) as well as their account information.

E-marketers must maintain the best possible security mechanisms to provide protection to the consumer's data and secure transactions to help consumers feel secure. If the security methods of the website are not state-of-the-art then consumer will not bother to shop there.

H11: Secure transactions positively affect consumer's trust.

6) Promotions: E-retailers might use deals/ offers and promotions on a product to encourage consumers to shop online [22]. Websites should advertise deals regarding a product on social media, and alert users on email address and mobile phones.

Promotions are another way to grab consumer's attention toward online shopping. If the consumer finds the deals interesting and feasible enough then the consumer will certainly buy the product and inform others about it.

H12: Promotions positively affects consumer's satisfaction.

7) Reliability: Reliability means the effectiveness of online order process i.e. getting the products delivered on time, refunds and reliable customer service. E- Retailers ought to provide refund policy for the customers who wish to return the product or replace it for another, if they are not satisfied with it.

H13: Reliability positively affects consumer's trust.

\section{CAUSAl LoOP Diagram (CLD)}

Causal loop diagram is a system dynamics tool, used to visualize relationship between different variables in term of cause and effect. It is a great way to portray how the factors affecting consumer's behavior are interrelated and how they associate with customer's satisfaction.

The thirteen hypothesis formed about the consumer's behavior in an online shopping environment are visualized here in a causal loop diagram. There are several factors that positively affect consumer's satisfaction including: Interactivity and UI Quality of the website, Convenience, Responsiveness, Promotions, Ease of use, decision aids and price. Security, Reliability, Brand, Demographics and Availability of product information positively affect customer's trust.

Trust increases the end user's satisfaction with the website and their loyalty to the website as they visit the website for repurchase of items. Customer loyalty increases the productivity of the website. 


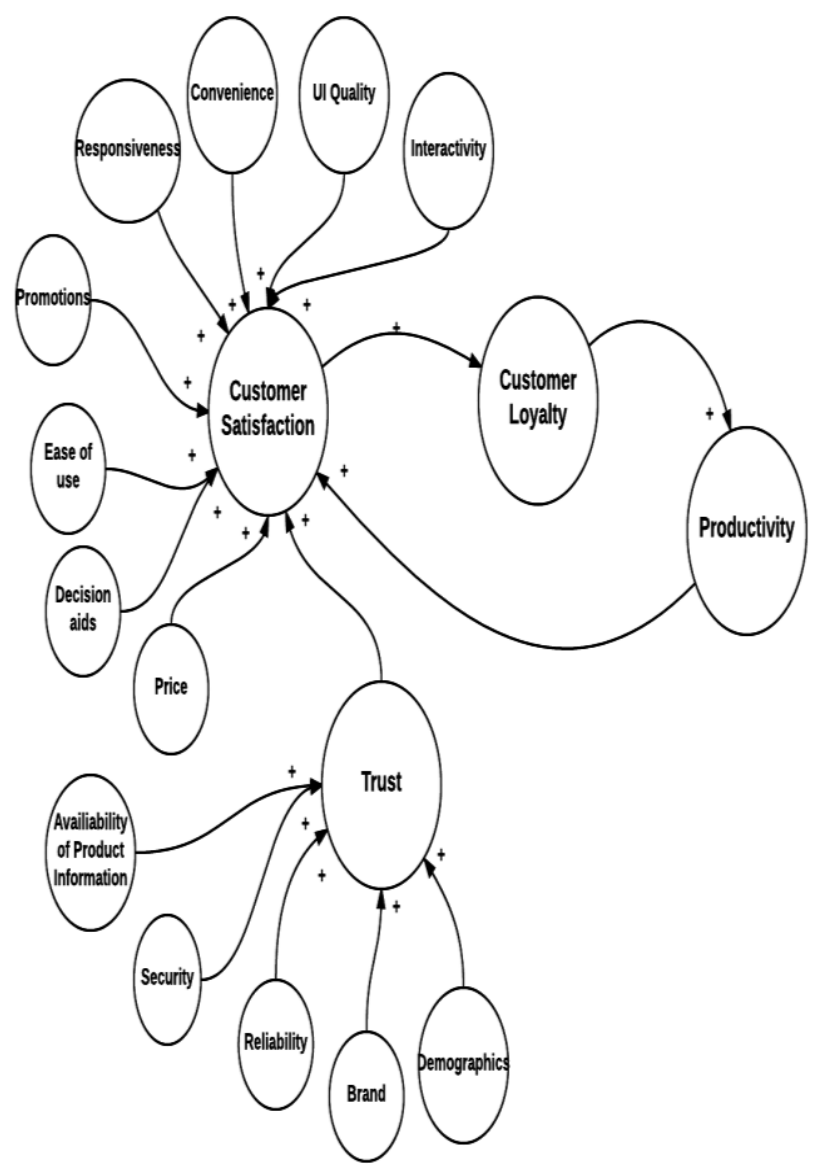

Fig. 2. Causal loop diagram for this scenario

\section{SIMULATION AND RESUlTS}

This section contains the simulation of the causal loop diagram in iThink tool and the results found which are also generated through the features (Table Pad and Graph Pad) of the same tool.

A questionnaire was developed from thirteen hypothesis discussed in Section-V to collect data. 20 questions having Likert scale were asked in the online survey from 100 participants. The Likert scale range started from strongly disagree having value of 1 , to strongly agree having the highest value of 7 . The data was analyzed to find the mean values of the factors and added to a simulation via iThink (i.e. by isee systems).

There are some negative factors which contribute to the loss of consumer's trust such as: no delivery risk, unsecure transactions, loss of privacy, bad UI quality, poor website content and poor customer support service. For this simulation RANDOM function is used to calculate trust lost, because these negative factors may vary in websites. iThink is a system dynamics tool having an intuitive icon-based graphical interface. There have been many studies regarding factors affecting consumer's online behavior and for evaluation of eCommerce websites.

This simulation showed how the user's trust and satisfaction directly impact productivity of the eCommerce website.

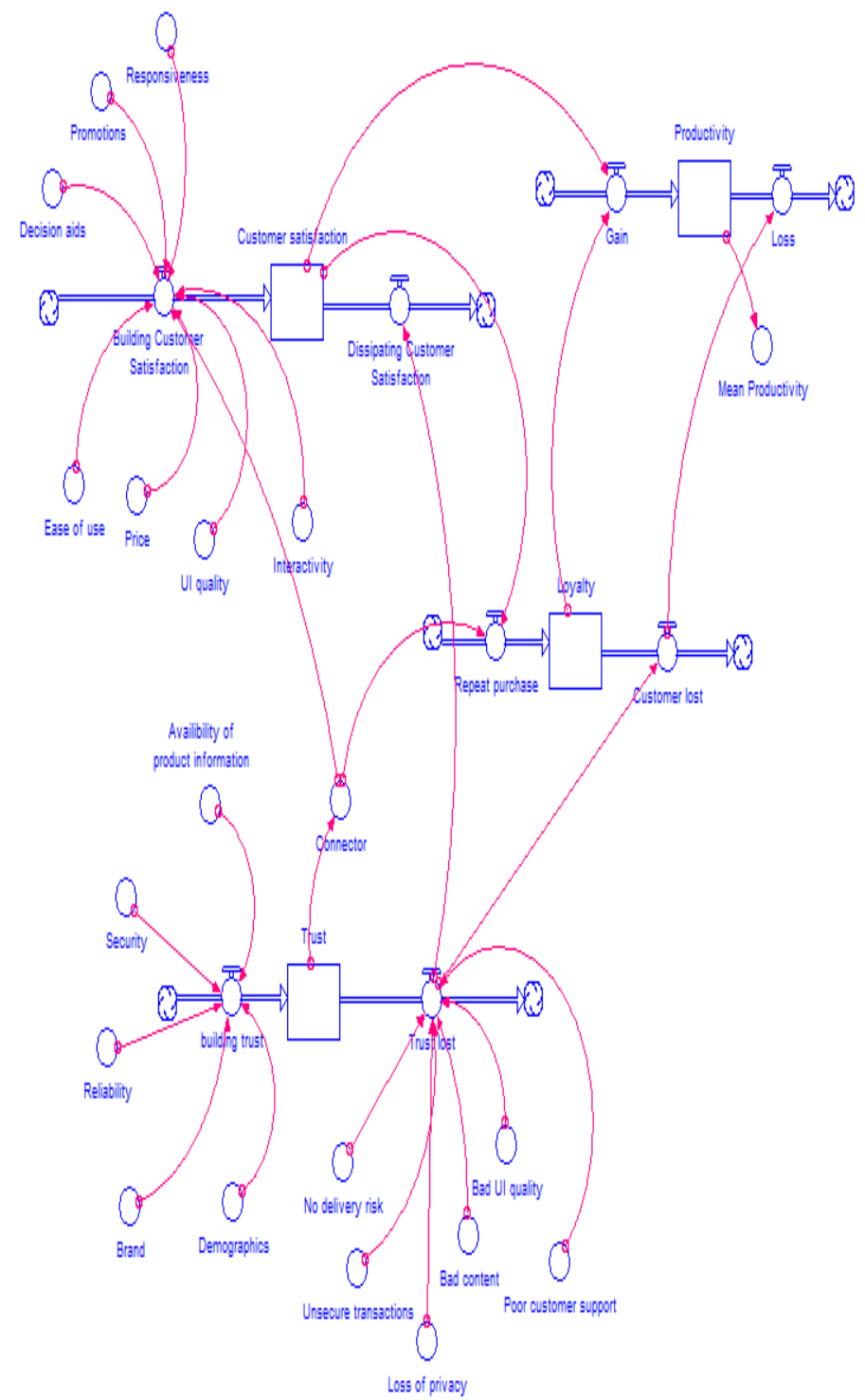

Fig. 3. Model of the causal loop diagram in iThink

TABLE II. TABUlar DATA OF 20 YeARS SHOWING INCREASE IN TRUST LEADS PRODUCTIVITY

\begin{tabular}{|c|c|c|c|c|c|c|}
\hline $9: 07$ PM 11/4/2016 & & \multicolumn{3}{|c|}{ Table 1 (Untitled Table) } & \multicolumn{2}{|c|}{ ? 洪昌 } \\
\hline Years & Customer sat T T & & Loyalty & \begin{tabular}{|l|} 
Productivity \\
\end{tabular} & Mean Product & \\
\hline Initial & 0.00 & 0.00 & 0.00 & 0.00 & 0.00 & \\
\hline & 32.64 & 22.29 & 3.55 & 0.00 & 0.00 & \\
\hline 4 & 89.15 & 45.84 & 65.83 & 51.93 & 0.52 & \\
\hline 3 & 173.24 & 73.38 & 220.97 & 288.70 & 2.87 & \\
\hline & 275.50 & 93.70 & 488.08 & 761.62 & 7.62 & \\
\hline & 404.69 & 118.19 & 891.05 & $1,869.77$ & 18.90 & \\
\hline & 554.22 & 140.82 & $1,451.93$ & $3,212.37$ & 32.12 & \\
\hline 7 & 730.83 & 186.28 & $2,199.81$ & $5,528.79$ & 56.27 & \\
\hline & 927.73 & \begin{tabular}{|c|}
187.85 \\
\end{tabular} & $3,152.84$ & $8,845.52$ & 88.48 & \\
\hline & $1,151.20$ & 213.47 & $4,338.13$ & $13,411,72$ & 134.12 & \\
\hline 10 & $1,390.98$ & 232.04 & $5,770.41$ & $19,478.99$ & 194.79 & \\
\hline 11 & $1,663.00$ & 253.19 & $7,473.00$ & $27,328.67$ & 273.29 & \\
\hline 12 & $1,941.09$ & 277.90 & $9,473.13$ & $37,286.21$ & 372.86 & \\
\hline & $1^{2 n 205}$ & neat in & 11701 not & $10 \mathrm{ann} 77$ & $102 \mathrm{ng}$ & \\
\hline
\end{tabular}




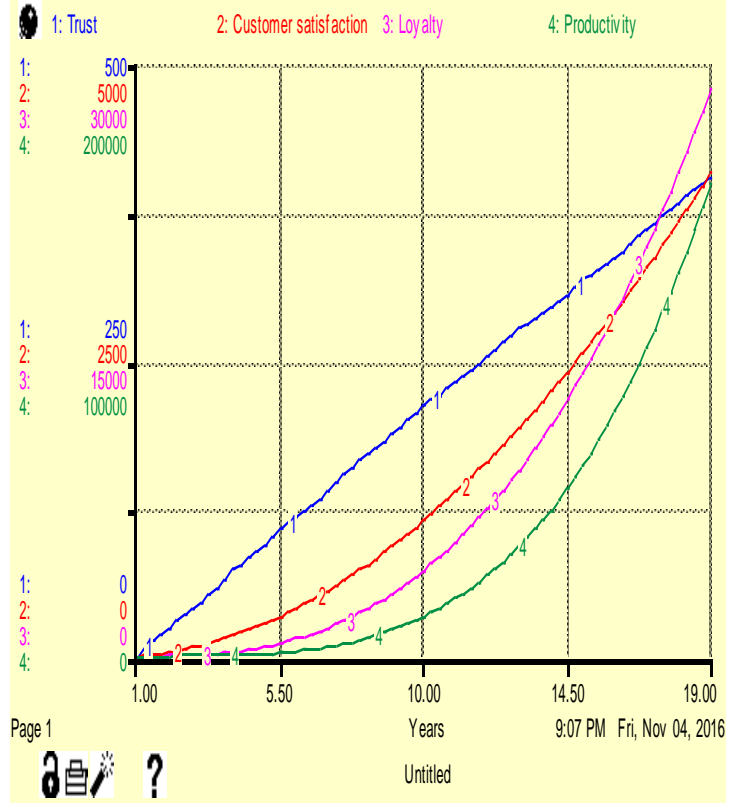

Fig. 4. Simulations Graph showing increase in productivity through trust

In Table II and figure 4 data of 20 years of an ecommerce website is shown. It shows that trust increases consumer's satisfaction which in turn increases customer loyalty. Customer loyalty refers to when the consumers come back on the website for repeat purchase. Consumer's satisfaction and e-loyalty increases productivity of the website. Retailers and marketers can benefit from using this model.

\section{CONCLUSION}

As opposed to other studies regarding factors affecting consumer's online behavior, this work provides a comprehensive amount of factors and a novel approach to represent the conceptual model.

In aforementioned work, different socio-technical factors (attributes) are highlighted, integrated and delineated comprehensively in graphical representation (simulations) those affects the way the consumer shop online. A conceptual methodology is proposed in this work to estimate and validate the success of the eCommerce website (web portal). The simulations and validations of the proposed model is then validated latter via iThink which further depicts (data \& results) productivity increases if consumer is satisfied and trust the system.

This proposed methodology is beneficial to developers as well as for retailers. Developers can keep in mind the technical aspects (attributes) while developing the system to provide user the best experience possible and latter retailers can increase the productivity of their organization.

\section{REFERENCES}

[1] Koyuncu and G. Bhattacharya, "The impacts of quickness, price, payment risk, and delivery issues on on-line shopping", The Journal of Socio-Economics, vol. 33, no. 2, pp. 241-251, 2004.

[2] N. Li and P. Zhang, "Consumer online shopping attitudes and behavior: An assessment of research", AMCIS 2002 Proceedings, p. 74, 2002.
[3] T. Liang and H. Lai, "Electronic store design and consumer choice: an empirical study", System Sciences, 2000. Proceedings of the 33rd Annual Hawaii International Conference, 2000.

[4] S. Kuester, MKT 301: Strategic Marketing \& Marketing in Specific Industry Contexts, University of Mannheim, p. 110,2012.

[5] A. Smith and W. Rupp, "Strategic online customer decision making: leveraging the transformational power of the Internet", Online Information Review, vol. 27, no. 6, pp. 418-432, 2003.

[6] C. Park and Y. Kim, "Identifying key factors affecting consumer purchase behavior in an onli1ne shopping context", Intl $\mathbf{J}$ of Retail \&DistribMgt, vol. 31, no. 1, pp. 16-29, 2003.

[7] S. Akbar and P. James, "Consumers' attitude towards online shopping: Factors influencing employees of crazy domains to shop online", Journal of Management and Marketing Research, vol. 14, no. 3, 2013.

[8] N. Li and P. Zhang, "Consumer online shopping attitudes and behavior: An assessment of research", AMCIS 2002 Proceedings, p. 74, 2002.

[9] S. F. A. Aghdaie, A. Piraman and S. Fathi, "An analysis of factors affecting the consumer's attitude of trust and their impact on internet purchasing behavior", International Journal of Business and Social Science, vol. 2, no. 23, pp. 147-158, 2011.

[10] W. Hung and R. McQueen, "Developing an evaluation instrument for ecommerce web sites from the first-time buyer's viewpoint", Electronic Journal of Information Systems Evaluation, vol. 7, no. 1, pp. 31-42, 2004.

[11] W. DeLone and E. McLean, "Measuring e-commerce success: Applying the DeLone\& McLean information systems success model", International Journal of Electronic Commerce, vol. 9, no. 1, pp. 31-47, 2004.

[12] T. Lauraéus, T. Saarinen and A. Öörni, "Factors Affecting Consumer Satisfaction of Online Purchase," System Sciences (HICSS), 2015 48th Hawaii International Conference on, Kauai, HI, 2015, pp. 3364-3373. doi: 10.1109/HICSS.2015.406

[13] G. Hofstede, "The business of international business is culture", International Business Review, vol. 3, no. 1, pp. 1-14, 1994.

[14] P. Kotler and G. Armstrong, Principles of marketing. Upper Saddle River, N.J.: Pearson Prentice Hall, 2006.

[15] G. Heim and K. Sinha, "Operational Drivers of Customer Loyalty in Electronic Retailing: An Empirical Analysis of Electronic Food Retailers", Manufacturing \& Service Operations Management, vol. 3, no. 3, pp. 264-271, 2001.

[16] J. Joergensen and J. Blythe, "A guide to a more effective World Wide Web presence", Journal of Marketing Communications, vol. 9, no. 1, pp. 45-58, 2003.

[17] Y. Bart, V. Shankar, F. Sultan and G. Urban, "Are the Drivers and Role of Online Trust the Same for All Web Sites and Consumers? A LargeScale Exploratory Empirical Study", Journal of Marketing, vol. 69, no. 4, pp. 133-152, 2005.

[18] A. Schlosser, T. White and S. Lloyd, "Converting Web Site Visitors into Buyers: How Web Site Investment Increases Consumer Trusting Beliefs and Online Purchase Intentions", Journal of Marketing, vol. 70, no. 2, pp. 133-148, 2006.

[19] C. Quinn, "How leading-edge companies are marketing, selling, and fulfilling over the Internet", Journal of Interactive Marketing, vol. 13, no. 4 , pp. 39-50, 1999.

[20] G. Häubl and V. Trifts, "Consumer Decision Making in Online Shopping Environments: The Effects of Interactive Decision Aids", Marketing Science, vol. 19, no. 1, pp. 4-21, 2000.

[21] A. Bhatnagar and S. Ghose, "A latent class segmentation analysis of eshoppers", Journal of Business Research, vol. 57, no. 7, pp. 758-767, 2004.

[22] D. S. Zhu, M. J. Kuo and E. Munkhbold, "Effects of E-Customer Satisfaction and E-Trust on E-Loyalty: Mongolian Online Shopping Behavior," 2016 5th IIAI International Congress on Advanced Applied Informatics (IIAI-AAI), Kumamoto, 2016, pp. 847-852.

[23] V. Shankar, G. Urban and F. Sultan, "Online trust: a stakeholder perspective, concepts, implications, and future directions", The Journal of Strategic Information Systems, vol. 11, no. 3-4, pp. 325-344, 2002. 
[24] A. Chandra and D. Sinha, "Factors Affecting the Online Shopping Behaviour: A Study With Reference to Bhilai Durg", International Journal of Advanced Research in Management and Social Sciences, vol. 2, no. 5, 2013.

[25] M. Moshrefjavadi, H. Rezaie Dolatabadi, M. Nourbakhsh, A. Poursaeedi and A. Asadollahi, "An Analysis of Factors Affecting on Online Shopping Behavior of Consumers", International Journal of Marketing Studies, vol. 4, no. 5, 2012.
[26] N. Khanh and G. Gim, "Factors Affecting the Online Shopping Behavior: An Empirical Investigation in Vietnam", International Journal of Engineering Research and Applications, vol. 4, no. 2, pp. 388-392, 2014.

[27] H. Uzun and M. Poturak, "Factors Affecting Online Shopping Behavior of Consumers", European Journal of Social and Human Sciences, vol. 3, no. 3, pp. 163-170, 2014.

[28] Sinha and J. Kim, "Factors affecting Indian consumers' online buying behavior", Innovative Marketing, vol. 8, no. 2, pp. 46-57, 2012. 